Wiriters are given a "DSC Style Manual" and their work is reviewed and monitored for up to six months to ensure that they are meeting our high standards.

All this training and monitoring is necessary because we can no longer assume that possession of a university degree automatically means that the university graduate has good writing skills and can think logically and clearly. In fact, a great number of welleducated individuals pepper their texts with words and phrases such as, "scenario, back-burner, head honcho, and bucking it up the line"! One recent graduate stated in her résumé that "...(I) enjoy the creative challenge involved in the application of dialectical reasoning in any subject matter requiring a synthesis"!:

We try to train our writers to write clear, concise texts that are easily understandable. Superfluous wording, bureaucratic gobbledegook and the latest jargon are not acceptable. The basic idea is to get the message across in good, plain English. The text may not sound as important once we have stripped it down but the message will certainly be much clearer.

So, do not believe all those stories claiming that government letters and texts are all complex and incomprehensible. We are doing our best to communicate clearly and simply and, remember, if you receive a letter stating -

"It must be recognized that this is not a normal business transaction but rather a political item so far as the U.K. authorities are concerned, accordingly, whilst continued efforts will be made by all Canadian officlals the likelyhood (sic) of any successful completion in the forseeable (sic) future is most unlikely." -it won't be from Transport Canada!

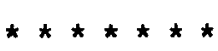

Over the past twelve years, Serafina Sebastyan has had experience in editing, writing and publishing in several federal government departments. She now manages the Executive Correspondence Unit of Transport Canada and holds a B.A. Honours in English and French Literature and a Master's degree In French Language and Literature.

\section{WRITING WORD PROCESSOR MANUALS FOR A LAY PUBLIC}

Karin Montin

I am going to discuss some of the problems involved in writing easy-to-understand instructions for word processing aimed chiefly at secretaries and typists.

In particular, I will be looking at some ways of adapting vocabulary to the reader's experience and reading ability and conforming sentence structures to a few rules of thumb.

My experience has been as a writer of user training manuals for a large manufacturer of word processors.

Writing user documentation for word processing is technical writing, since it involves describing and explaining complex electrontc functions. It can equally well be described, however, as nontechnical writing, since it is intended for nontechnicians.

\section{WORD PROCESSING}

A word processor is a specialized computer that can be most simply described as a fancy typewriter. It looks like a combination typewriter and television screen, although the typewriter is split into keyboard and printer. The keyboard has some extra keys which make 1t possible to do more than just type.

A word processor can do many things, but its primary function is to display what you have typed before you print it on paper. Since typing and printing are separate steps, it 1s possible to make any number of changes to the typed page before it is committed to paper. The second major function is to store a typed page on disk the way a tape recorder stores a song on tape, making it possible to play 
back the typed page rather than retype it when you what to use it again.

In between typing and printing there is room for a lot of change to the page, and every type of change requires a description and explanation for the user. This, of course, is where technical writers come in.

\section{THE ROLE OF THE USER DOCUMENTATION WRITER}

The role of the writer of user documentation is to interpret technical information for the lay public. The written information that the user documentation writer recelves comes from another type of technical writer, someone much closer to the technical aspects of the development of the hardware, or equipment, and soft-

ware, or programmes to be documented.

The Information provided by these writers is called technical spec1fications, or specs. Specs describe the way a machine or programme 1 s supposed to work in 1 ts 1 deal form and are updated whenever changes are made. New versions of software are released periodically, too.

Writers must make sure that they are always working with the most recent software avallable, and that they have the paper documentation to accompany $1 t$.

So writers do more than just write. Often they are testers of new features and are expected to find things that don't work. This makes it more difficult to document the feature, but it is a good way to get to know the features inside out.

\section{TARGET POPULATION}

Before anyone can start writing a user manual, some research needs to be done to determine just who the manual is for. It is perhaps the writer's role to ask the proper questions but it may be someone else's job to find out the answers.

First of all, the design team had a certain target population in mind when they invented the machine or programme. In the case of word processors, they were certainly thinking of the people who are used to using typewriters. In the case of other types of computers, or of certain types of programmes for word processors, another group may be targeted, management, for example. The designers also have an Idea of what the system can and should be used for.

Next, the marketing team has an Idea of who they want to buy the system. The two targets are not always identical.

Once you have determined a general target group, you must find out more specific information about the members of that group: age, education, and interests, for example. You also need to know the circumstances under which the manual will most likely be used: with or without a teacher or supervisor, in a busy office, on lunch hours, in a quiet place with no disturbance.

The readership of manuals is composed principally of secretaries and typists, with a small but growing number of professionals. Questionnaires sent out with manuals and returned by users show that the secretaries have a high school education, while a few also completed secretarial training, and a smaller number attended college or untversity.

Other surveys show that the average reading level of high school graduates is about grade 6 . To me this implies a judgment probably based on formal schemes of measuring sentence structure and vocabulary. Since I do not make use of such schemes, I just think about books I read when I was in grade 6 and those I have read recently that are intended for that grade level.

Personal contact with people using the manuals has led me to the Inevitable conclusion that they do not like to read. They therefore do not read any more than they deem absolutely necessary. This means that a great many of them skip anything that is not labelled practice, returning to read the background information only when something unexpected occurs. A formal Dutch study also showed the same thing [see Editorial Eye, April 1984].

The two main problems to consider in writing for an audience such as the one $I$ have fust described are their lack of reading skills and their small interest in reading. 
Writers must remember that no mater how easy the prose is to understand, 1t does no good if the learner does not read it. A major difficulty is combining background information with practice in a way that allows the learner both to do the exercise and obtain a verifiable result, and to apply the skill generally on the job.

One theory of teaching is that first the general principles should be explained, then the learner should practice them. In my experience, this method does not elicit the best response from learners on their own. They prefer, as $I$ have mentioned, to skip ahead to a part of the lesson that looks like a practice, where they are told to do steps 1,2 , and 3 to get a specified result. Often they do not read anything about the generalities unless something happens that bothers them.

This habit can lead to problems later in the lesson, as you can easily imagine. Frequently, in the next practice they are told to do something which requires the use of the skill they were supposed to have been taught in the last section, or, just as bad, requires the material result of the last practice.

When they need to use a skill after a lesson, learners who do not understand of ten do either exactly the same thing as in the exercise, to the letter, or don't do it at all. For example, if told in a practice to put a page numbering symbol on line 3 and centre $1 t$, many learners will forever centre page numbers on line 3 rather than put them in a location of their own choosing.

There are a few techniques to make the written material more appealIng. Cartoons liven things up, diagrams often explain more than words, and lots of white space makes a page less intimidating. In short, the less writing there is, the better.

But this difficulty in presenting material is not the one $I$ wish to address in detall. There are many theories about learning and the order in which to present new concepts to get the best results.

Instead, I would 11ke to look at some ways of keeping prose as clear and simple as possible, using for raw material some examples of engineering jargon that need to be drastically cleaned up before novices can have the faintest 1 dea of what it 1 s trying to say. My examples are drawn mostly from technical specifications describIng a vartety of functions, and manuals published to accompany word processors. A couple are from a manual for a microcomputer and a popular type of word processing software.

\section{SENTENCE STRUCTURE}

As I have mentioned, I do not make use of any codified methods of measuring sentence clarity. There are methods that count words per sentence, syllables per word, and so on, but they can be safely avoided, if common sense is used instead. Use your own, and especially, use that of the target population.

It seems to me that the best foundation for an instruction manual of any sort consists of sentences kept short and simple; this means a minimum of subordinate clauses, absolutely no formers or latters, and a lot of active verbs. Although I have fust said I don't believe in counting words per sentence, I do think that aim-

ing for sentences no longer than five words 18 a good idea, though certainly not to be followed fanatically. A colleague has suggested an even more severé rule: reread the text a few weeks later and cross out every second word!

I do belleve in counting topics per page and pages per topic. I think it is best to confine the exposition of ideas to one idea per page and no more than two pages per 1dea. Even if this is 1mpossible, as is of ten the case, it 18 essential to start a new page for each new 1dea. Above all, title each topic and subtopic clear1y. This means that the wording of the title must indicate simply and concisely what the topic 1s, and the position of the title and even its typeface must draw it to the reader's attention.

\section{VOCABULARY}

One reason for not counting syllables is that many polysyllabic words, even of a technical nature, are easily understood by readers 
because they are in common use. In the area of vocabulary, rule number one is to employ terms already familiar to users.

As time goes on, more and more computer terms are becoming part of everday language. Just think of input and bugs, once exclusively computer jargon and now well established in general usage. More recently video has come into wider use than $i l$ enjoyeu just a coupie of years ago. All the same, think twice about any technical term.

Many words take on new meanings in a technical context. In word processing, for example, recall, memorize, text, and program take on spectalized meanings. Other terms, such as justification, mean the same thing in another field, but are not in everday use. A number of word processing terms are straight from data processing --parconeter, command, execute and current, to list a few.

I think it is worthwhle attempting to replace computer terms with others perhaps more familiar to users, and in some cases more frlendly. Abort, kill, execute, and command, for example, are rather hostile terms, not designed to put most people at ease.

Entering is not a familiar activity to most secretaries, and manual means something you do by hand.

Writers can reduce confusion in the minds of readers by avoiding the use of unfamillar terms or familiar terms with new meanings. When you consider that some people, when told to memorize a page, actually wonder whether they are supposed to stare at the screen until they know the page by heart, you will understand why I am emphasizing rules that seem quite elementary.

Another solution to the vocabulary problem is to define your terms the first time you use them and stick to them. Avold synonyms like the plague. Here is an example of synonymy: video, VDT, display monitor, and $C R T$ all mean the screen of a word processor or computer. The manual for a product should use one term for screen throughout. Th1s rule applies to auxiliary manuals that may be acquired later.
A glossary in a central location is a helpful tool to the reader, but remember to Indicate where it can be found. Remember to make the definition readable and comprehensible. And remember to define the terms used, not synonyms. One computer glossary I have seen defines cold start, but the term cold boot appears throughout the manual. Bootstrap or boot is included--1t is defined as "To Initia11ze a system from a 'power-off' condition. This is usually a small program that is run immediately upon power-up." This is an example of how not to write a glossary.

Some words can just be left out. For example, automatic is a word that is easy to overuse. Everything a word processor does is automatic, so it can often be omitted. Current is another word easily dispensed with. Since the current cursor position is simply the position of the cursor when you are looking at $1 \mathrm{t}$, why bother spec1fylng?

Now let's look at some examples of technical and not so technical writing.

The left hand column contains technical terms with an example of how they are used. The right hand column contains suggestions for rewriting.

$\begin{array}{ll}\text { abort, kill } & \text { cancel } \\ \text {-ABORT kill background fob } & \text {-CANCEL stop background fob }\end{array}$

current (omit)

This Instruction displays the current amount of unused space on the disk unit.

This instruction displays the amount of space left on the diskette.

\section{default}

The default margins are 10 and 80 .

preset, standard (or omit)

enable, disable

The printer must be enabled before programing the system. and 80 .

turn on, turn of $f$

Turn on the printer before you program the system. 
load a program

Load the repagination diskette. function)

Program the system with the repagination diskette.

\section{string}

word, phrase, name

A name may be an alphabetic and/ or numeric string between 1 and 10 characters in length, and with no embedded space characters in the string. The string must begin with an alphabetic character.

\section{SENTENCE STRUCTURE}

The technical writing is on the left. The less technical rewritten version is to the right.

The FILE command allows access to the FILE command tree.

FILE commands give you access to the items stored in your filing application. Once the FILE command tree is
entered, commands such as COPY,

Once you start a FILE command DELETE and MOVE may be performed. such as COPY, DELETE and MOVE.

The personal work area of any given user is called 'name' where 'name' is the user's $1 \mathrm{~d}$.

The name of your work area is the same as your user ID.

This instruction allows the user to configure the function's parameters.

With this instruction you can change the way the function works to suit your own needs.

For example, you can change the format settings.

A 11st of groups is a string of groupnames, separated by commas.

To list the groups, use commas --not spaces--to separate the names.

Enter the real name of the user. This is the user's actual name. It may be any alphabetic or numeric string, and must be en-

closed in " characters.
Type your real name in quotation marks.
A reminder is like an appointment but has fewer parameters.

A reminder is like an appointment, but includes only details concerning date and topic. An appointment Includes details of place, time, and attendees as well.

Enter a command keyword selected Select one of the following from one of the following. commands.

A keyword is selected by entering sufficient characters to uniquely identify one of the keywords. Following this, pressing the EXEC key will cause the cholce to appear on the command line in 1ts fully expanded form and the next aet of keywords of keywords will appear on the prompt line.

Reformat the word processing data to be used so that the left margin is at the left side of the page and the right margin is located at the position of the 3270 screen to be used (i.e. at column 80 or 1ess).

Select a command by typing enough letters to identify the word you want. Then press EXEC
Reformat the word processing texts you wish to use so that the left margin 18 at 1 and the right margin 18 at 80 or less.
Recognizable words can be buflt from the following set of characters :

--lowercase letters a-z --uppercase letters A-Z

--lowercase accented characters --uppercase accented character --digits $0-9$

--apostrophes

The clossary function allows you to enter previously memorized gloss character strings on the screen with minimum interruption of the typing process.
The dictlonary recognizes words made up of letters (uppercase or lowercase) or numbers. [Deal with apostrophes separately.]

You can use the glossary function to recall words and phrases rather than type them more than once. First memorize the words or phrases (called glosses) in a spectal glossary format. Then use the recall glossary instructo the recall glossary instruction to bring them to the screen as you need them. 
A gloss content can cross a page boundary.

A gloss can continue from one page to the next.

The gloss content 1s written to the video screen starting from the beginning of the gloss name on the video screen and observIng all the character entry

rules. If there are any char-

acters on the video screen,

where the gloss content is to

be written, they are over-

written, unless the video screen

is in insert mode.

"Beep" acoustic signal after depression of any key. Ind cates a machine malfunction.

A beep when you press a key means that the typewriter is not working properly.

When a character is typed, it is visualized on the display and transferred to the memory.

The system displays and memorizes characters as you type.

\section{CONCLUSION}

Simple testing will tell you whether a sentence 1s doing its job. Just ask several people what they understand the sentence to mean. Start with colleagues, then ask the department secretary, then, when the sentence is in what you think is 1 ts final form, ask a few "real people"--people who match the description of the user you are trying to reach. They are the ones whose opinton really counts.

\section{CBT - WHAT IT IS AND WHERE YOU MIGHT FIND IT}

\section{Patricia Lawson}

WHAT IS CBT?

CBT is when all learning occurs because of trainee-controlled interaction with a computer system. It is defined by the courseware (software used in an education application) run on a computer system. More than computer-aided instruction (CAI), where a computer augments traditional instructor-led seminars, it incorporates computer-managed Instruction (CMI), a computerized method of keeping trainee records. Moreover, it provides individualized instruction where trainees absorb information and demonstrate competence at their own level and pace.

\section{CBT IS COST AND LEARNING-EFFECTIVE}

CBT decreases course duration up to $30 \%$ over traditional methods. CBT also reduces the involvement of expensive subject experts in classroom instruction. It spreads their consultation time over an unlimited number of training sessions. This means that class size 181 imited only by the number of terminals at which trainees can work. With CBT, the main cash outlay is the capital invested for the hardware.

Statistics indicate that as much, if not more, learning results with CBT. This derives from the uniform quality of content and format, and from trainees being able to proceed at their own pace and being required to master content.

Ideally each course is developed by educational experts. This ensures content and format that is consistent and solid, and promotes uniform results. Every trainee is exposed to the same content and format, although not at the same pace or in the same sequence.

A large factor of competence is attitude. CBT has been proven to increase trainee satisfaction. Trainees do mofe than read and respond. They exercise control over the tasks, the sequence, the 